\title{
Is inflammation a potential therapeutic target in chronic thromboembolic pulmonary hypertension?
}

\author{
Rozenn Quarck and Marion Delcroix
}

Affiliations: Dept of Clinical and Experimental Medicine, Respiratory Division, KU Leuven - University of Leuven, Leuven, Belgium. Dept of Respiratory Diseases, University Hospitals Leuven, Leuven, Belgium.

Correspondence: Rozenn Quarck, Respiratory Division, Dept of Clinical and Experimental Medicine, Herestraat 49, B-3000 Leuven, Belgium. E-mail: rozenn.quarck@amed.kuleuven.be

0 @ERSpublications

Proof is still needed to confirm that modulation of inflammation can alter the disease process of CTEPH http://ow.ly/zN89N

Chronic thromboembolic pulmonary hypertension (CTEPH) is a rare but notoriously underdiagnosed complication of pulmonary embolism, which carries a poor prognosis if left untreated. CTEPH results from the obstruction of the pulmonary vascular bed by fibro-thrombotic material, which may completely occlude the lumen. Although massive or recurrent pulmonary embolism is thought to be the initiating event, a significant proportion of patients have no history of symptomatic pulmonary embolism and only a few patients with acute pulmonary embolism develop CTEPH [1]. As a consequence, the true prevalence and incidence of CTEPH remain unknown [2]. Current data, retrieved from registries, suggest that the incidence of CTEPH averages between three and 30 per million in the general population [3], and that the proportion of patients developing CTEPH after acute pulmonary embolism may vary between $0.1 \%$ and $9.1 \%$ [4]. The standard and potentially curative treatment for CTEPH is a surgical procedure, known as pulmonary endarterectomy (PEA) [5], which involves removing organised thrombi, neointima and media inner layers obstructing the pulmonary arteries (fig. 1b) [6]. PEA, when performed in experienced centres and on selected patients, shows low perioperative mortality, and provides major improvements in haemodynamics, symptoms and survival [7]. Moreover, CTEPH is a "dual" pulmonary vascular disorder combining major vessel obstruction and small vessel arteriopathy, which is histologically indistinguishable from idiopathic pulmonary arterial hypertension (PAH) in the non-occluded lung areas [8]. As a consequence, PAH-targeted therapy, including prostacyclin analogues, endothelin-1 receptor antagonists and phosphodiesterase-5 inhibitors, has been largely used in CTEPH [9] and should be considered for inoperable patients or patients with persistent pulmonary hypertension after PEA [10]. More recently, riociguat, a stimulator of soluble guanylate cyclase, has been approved for the treatment of inoperable CTEPH and persistent pulmonary hypertension after PEA, on the basis of demonstrated improvements in haemodynamics and exercise capacity [11].

The reasons why acute embolic obstruction does not resolve and causes pulmonary hypertension in a minority of patients remain unclear. Incomplete resolution of thrombi is often observed after acute pulmonary embolism [12] and patients displaying persistent occlusions also have higher mean pulmonary arterial pressure compared with patients without any defect [13]. However, pressures usually remain within the normal range and patients do not show any exercise limitation. Various medical conditions, such as splenectomy, chronic inflammatory disorders, ventriculoatrial shunts, infections or cancer, are associated with CTEPH [4], and CTEPH is more common in people with non-O blood groups [14, 15]. In addition to an impaired balance between coagulation and fibrinolysis, and deficient angiogenesis with impaired

Received: June 302014 | Accepted after revision: July 232014

Conflict of interest: Disclosures can be found alongside the online version of this article at erj.ersjournals.com

Copyright @ERS 2014 
a)

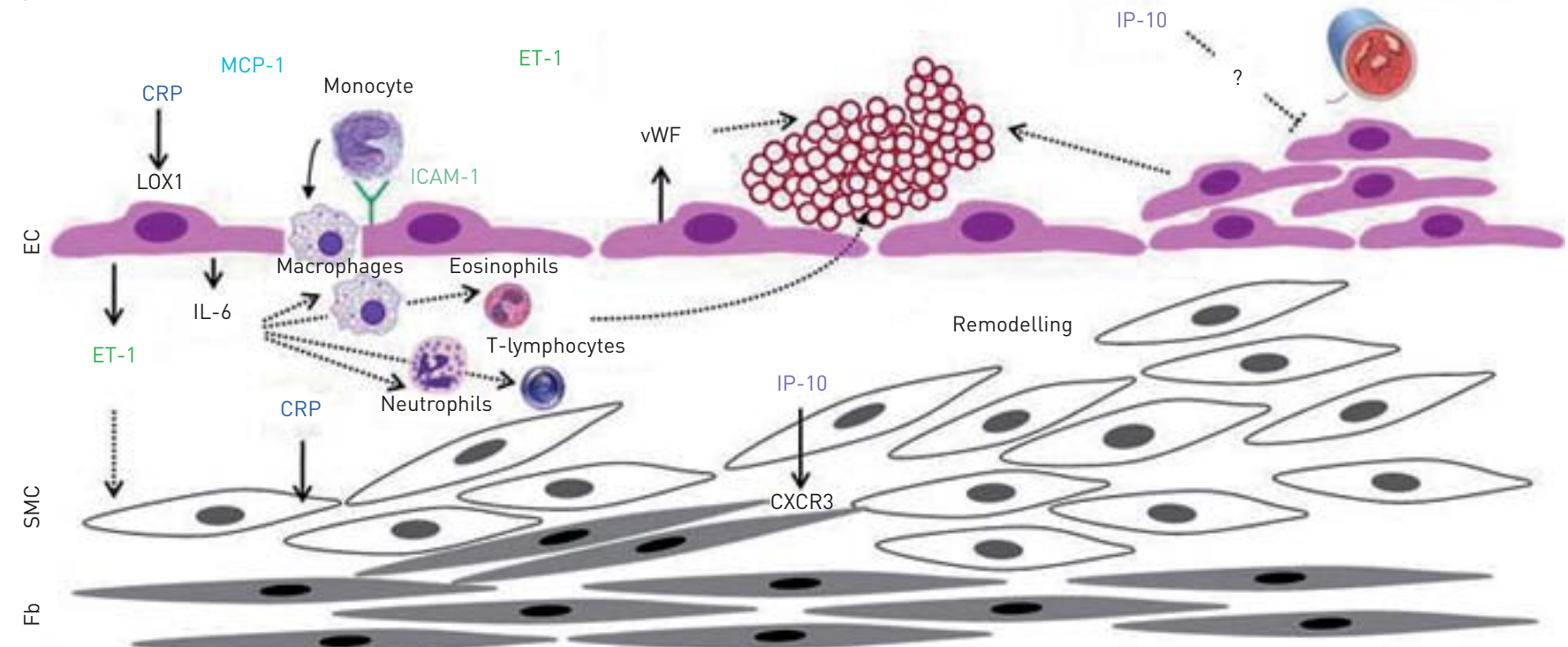

b)

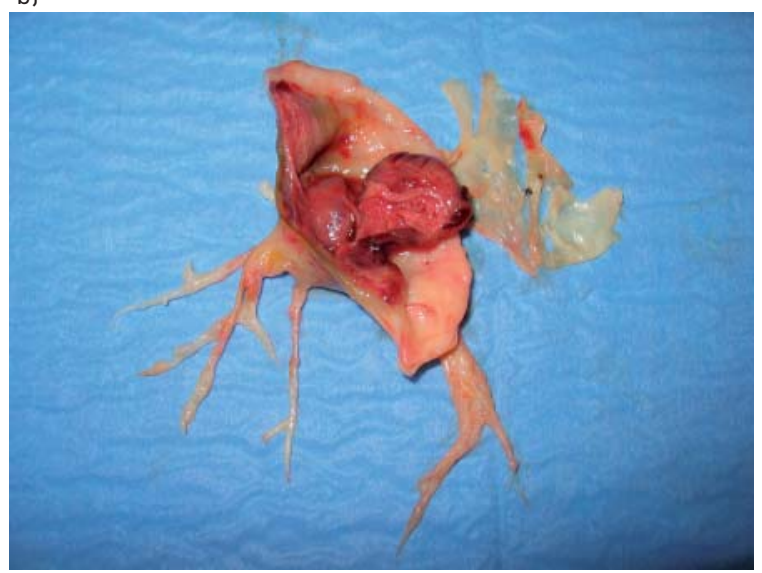

c)

\begin{tabular}{|c|c|c|}
\hline Dogma & In situ observation & In vitro findings \\
\hline Inflammation & $\begin{array}{l}\text { Cytokines, chemokines } \\
\text { Inflammatory cells }\end{array}$ & $\begin{array}{l}\text { Release of cytokines } \\
\text { Adhesion of monocytes }\end{array}$ \\
\hline Thrombosis & Thrombotic material & Secretion of vWF \\
\hline Impaired angiogenesis & $\begin{array}{l}\text { Recanalised lesions } \\
\text { IP-10 secretion }\end{array}$ & $\begin{array}{l}\text { Inhibition of VEGF-induced sprouting by } \\
\text { CTEPH-derived thrombotic material }\end{array}$ \\
\hline Remodelling & $\begin{array}{l}\text { Neointima formation } \\
\text { Media thickening }\end{array}$ & $\begin{array}{l}\text { SMC proliferation and migration } \\
\text { Fibroblast migration }\end{array}$ \\
\hline & \multicolumn{2}{|c|}{$\begin{array}{c}\text { Unresolved thrombus } \\
\text { Fibro-thrombotic material } \\
\text { Persistence of obstructed pulmonary arteries }\end{array}$} \\
\hline
\end{tabular}

FIGURE 1 a) Schematic view of potential mechanisms contributing to persistent vessel obstruction and chronic thromboembolic pulmonary hypertension (CTEPH) pathogenesis. b) Fibro-thrombotic material obstructing pulmonary arteries collected during pulmonary endarterectomy. c) Information from in situ to in vitro findings. MCP-1: monocyte chemoattractant protein; CRP: C-reactive protein; LOX1: lectin-type oxidised low-density lipoprotein receptor; ET-1: endothelin-1; IL-6: interleukin-6; ICAM-1: intercellular adhesion molecule-1; SMC: smooth muscle cell; Fb: fibroblasts; vWF: von Willebrand Factor; IP-10: interferon- $\gamma$-induced protein-10; VEGF: vascular endothelial growth factor.

thrombus recanalisation, inflammatory thrombosis has been suggested to be involved in the pathogenesis of CTEPH [3] (fig. 1a). Although the role of inflammation in the pathogenesis of PAH has been extensively documented both in PAH animal models and patients, the involvement of the inflammatory process in the pathogenesis of CTEPH remains elusive.

In this issue of the European Respiratory Journal, ZABINI et al. [16] hypothesise that cytokines could mediate the obstructive remodelling of pulmonary arteries in CTEPH. They profiled a broad range of cytokines, including interleukin (IL)-8, IL-6, interferon- $\gamma$-induced protein (IP)-10, monocyte chemoattractant protein (MCP)-1, monokine induced by interferon- $\gamma$ (MIG), RANTES, CX3CL1, macrophage inflammatory protein (MIP) $1 \alpha$ and CXCL12, in PEA tissue, PEA tissue supernatant and in serum of newly diagnosed CTEPH patients, and identified IP-10 as a potential pathogenic factor for CTEPH. IP-10, also known as CXCL10, is a small cytokine belonging to the CXC chemokine family that is secreted in response to interferon (IFN)- $\gamma$ by several cell types, including monocytes, endothelial cells and fibroblasts [17]. IP-10 is a chemoattractant for monocytes/macrophages, T-cells, natural killer cells and dendritic cells. It promotes T-cell adhesion to endothelial cells and inhibits bone marrow colony formation and angiogenesis [18, 19].

The authors used a translational approach combining analysis of PEA tissue, serum from CTEPH patients and in vitro assays with clinical parameters to show that IP-10 is negatively correlated with the 6-min 
walking distance (6MWD), the primary end-point used in most randomised clinical trials, and with cardiac output. The authors also found a correlation between circulating IL-6 and right atrial pressure (RAP), pulmonary vascular resistance (PVR) and N-terminal pro-brain natriuretic peptide (NT-proBNP). KIMURA et al. [20] previously showed a correlation between plasma and tissue expression of the CCL2 chemokine MCP-1 with elevated PVR. Elevated circulating C-reactive protein (CRP) levels, observed in unselected CTEPH patients, were significantly decreased following PEA [21]. Similarly, in this latest CTEPH cohort $(\mathrm{n}=127)$, plasma CRP levels significantly correlated with RAP and negatively with 6MWD (unpublished data). In the aforementioned studies, inflammatory cytokines could be markers of right heart function failure rather than vascular disease.

Interestingly, the authors suggested a pathogenic role for IP-10 by showing in vitro inhibition of IP-10induced fibroblast migration by antibodies against CXCR3, the receptor for IP-10. A bundle of converging evidence further supports the hypothesis that IP-10 and IFN- $\gamma$ signalling pathways are potential key players in the pathogenesis of CTEPH (fig. 1a) and not simply innocent bystanders: 1) medical conditions with an inflammatory component, including staphylococcal infection, splenectomy, inflammatory bowel disease and osteomyelitis, are risk factors for CTEPH [22], and are associated with IP-10 secretion and/or elevated circulating IP-10 [23-25]; 2) IFN- $\gamma$ signalling could determine the relative pathogenicity of Staphylococcus aureus strains [26]; 3) venous thrombus resolution is misguided in the presence of S. aureus infection [27]; 4) IP-10 is an inhibitor of angiogenesis; and 5) defective angiogenesis delaying thrombus resolution is potentially involved in CTEPH [28], and could be promoted by splenectomy [29]. In our hands, CRP also seemed to contribute to the disease process by activating the nuclear factor (NF) $\kappa \mathrm{B}$ pathway, thereby inducing endothelial cell dysfunction in CTEPH (fig. 1a) [30,31]. The inflammatory hypothesis is further supported by the presence of eosinophils, macrophages, neutrophils and T-lymphocytes in the vascular material removed during surgery, as shown by ZABINI et al. [16] and by previous studies (fig. la and c) [6, 32, 33].

The exploratory study by ZABINI et al. [16] was conducted on a limited number of patients, although clinically well-characterised and consistently sex- and age-matched with healthy controls. The authors are aware of this limitation and propose further investigations extended to a larger number of patients in a prospective design. Accordingly, analysis of different potential inflammatory candidate mediators and development of therapeutic strategies targeting inflammation in this rare disease would require united efforts, possibly leaning on registries like the CTEPH European registry [1] and its worldwide extension (www.cteph-association.org/registries/cteph-registry). The authors remain very cautious regarding the impact of their study on possible therapeutic strategies, limiting themselves to speculating on the potential role of inflammatory mediators, such as IP-10, in the mechanisms underlying progressive obstruction of the pulmonary arteries in CTEPH (fig. 1a). However, the study by ZABINI et al. [16] displays other limitations: patient tissues and plasma samples were from separate cohorts, the origin of the supernatants was not clearly specified, and one may also wonder whether the healthy matched subjects were an optimal control population and whether idiopathic PAH patients would have been a better control cohort. In addition, it is unlikely to be possible to rule out any inflammatory disease and/or malignancy in a 60-year-old cohort.

Furthermore, most of the aforementioned studies have been performed using blood and tissue samples from patients at advanced stages of the disease. Prospective long-term follow-up studies gathering large numbers of acute pulmonary embolism patients, and combining clinical, biological and environmental parameters, are necessary to validate these pathogenic hypotheses. Similarly, development of accurate and relevant animal models clearly mimicking CTEPH pathobiology is needed, in addition to the recently developed models of abnormal venous thrombus resolution [28, 29] or of large vessel mechanical obstruction [34, 35].

Even if we do believe that inflammation is a potential therapeutic target in CTEPH, we are not yet ready for prime time. Actually, IP-10 is one potential player among many others and evidence that blocking the IP-10 receptor could alter disease progression and prevent or reverse advanced obstructive lesions (fig. 1b) is still missing.

\section{References}

Pepke-Zaba J, Delcroix M, Lang I, et al. Chronic thromboembolic pulmonary hypertension (CTEPH): results from an international prospective registry. Circulation 2011; 124: 1973-1981.

2 Tapson VF, Humbert M. Incidence and prevalence of chronic thromboembolic pulmonary hypertension: from acute to chronic pulmonary embolism. Proc Am Thorac Soc 2006; 3: 564-567.

3 Lang IM, Pesavento R, Bonderman D, et al. Risk factors and basic mechanisms of chronic thromboembolic pulmonary hypertension: a current understanding. Eur Respir J 2013; 41: 462-468.

Kim NH, Lang IM. Risk factors for chronic thromboembolic pulmonary hypertension. Eur Respir Rev 2012; 21: 27-31. Madani MM, Auger WR, Pretorius V, et al. Pulmonary endarterectomy: recent changes in a single institution's experience of more than 2,700 patients. Ann Thorac Surg 2012; 94: 97-103. 
6 Arbustini E, Morbini P, D’Armini AM, et al. Plaque composition in plexogenic and thromboembolic pulmonary hypertension: the critical role of thrombotic material in pultaceous core formation. Heart 2002; 88: $177-182$.

7 Jenkins DP, Madani M, Mayer E, et al. Surgical treatment of chronic thromboembolic pulmonary hypertension. Eur Respir J 2013; 41: 735-742.

8 Moser KM, Bloor CM. Pulmonary vascular lesions occurring in patients with chronic major vessel thromboembolic pulmonary hypertension. Chest 1993; 103: 685-692.

9 Delcroix M. Chronic post-embolic pulmonary hypertension: a new target for medical therapies? Eur Respir Rev 2013; 22: 258-264.

10 Kim NH, Delcroix M, Jenkins DP, et al. Chronic thromboembolic pulmonary hypertension. J Am Coll Cardiol 2013; 62: Suppl., D92-D99.

11 Ghofrani HA, D'Armini AM, Grimminger F, et al. Riociguat for the treatment of chronic thromboembolic pulmonary hypertension. N Engl J Med 2013; 369: 319-329.

12 Nijkeuter M, Hovens MM, Davidson BL, et al. Resolution of thromboemboli in patients with acute pulmonary embolism: a systematic review. Chest 2006; 129: 192-197.

13 Sanchez O, Helley D, Couchon S, et al. Perfusion defects after pulmonary embolism: risk factors and clinical significance. J Thromb Haemost 2010; 8: 1248-1255.

14 Bonderman D, Turecek PL, Jakowitsch J, et al. High prevalence of elevated clotting factor VIII in chronic thromboembolic pulmonary hypertension. Thromb Haemost 2003; 90: 372-376.

15 Bonderman D, Wilkens H, Wakounig S, et al. Risk factors for chronic thromboembolic pulmonary hypertension Eur Respir J 2009; 33: 325-331.

16 Zabini D, Heinemann A, Foris V, et al. Comprehensive analysis of inflammatory markers in chronic thromboembolic pulmonary hypertension patients. Eur Respir J 2014; 44: 951-962.

17 Luster AD, Unkeless JC, Ravetch JV. Gamma-interferon transcriptionally regulates an early-response gene containing homology to platelet proteins. Nature 1985; 315: 672-676.

18 Dufour JH, Dziejman M, Liu MT, et al. IFN-gamma-inducible protein 10 (IP-10; CXCL10)-deficient mice reveal a role for IP-10 in effector T cell generation and trafficking. J Immunol 2002; 168: 3195-3204.

19 Angiolillo AL, Sgadari C, Taub DD, et al. Human interferon-inducible protein 10 is a potent inhibitor of angiogenesis in vivo. J Exp Med 1995; 182: 155-162.

20 Kimura H, Okada O, Tanabe N, et al. Plasma monocyte chemoattractant protein-1 and pulmonary vascular resistance in chronic thromboembolic pulmonary hypertension. Am J Respir Crit Care Med 2001; 164: 319-324.

21 Quarck R, Nawrot T, Meyns B, et al. C-reactive protein: a new predictor of adverse outcome in pulmonary arterial hypertension. J Am Coll Cardiol 2009; 53: 1211-1218.

22 Bonderman D, Jakowitsch J, Adlbrecht C, et al. Medical conditions increasing the risk of chronic thromboembolic pulmonary hypertension. Thromb Haemost 2005; 93: 512-516.

23 Hosoki K, Nakamura A, Nagao M, et al. Staphylococcus aureus directly activates eosinophils via platelet-activating factor receptor. J Leukoc Biol 2012; 92: 333-341.

24 Torrence AE, Brabb T, Viney JL, et al. Serum biomarkers in a mouse model of bacterial-induced inflammatory bowel disease. Inflamm Bowel Dis 2008; 14: 480-490.

25 Wright KM, Friedland JS. Differential regulation of chemokine secretion in tuberculous and staphylococcal osteomyelitis. J Bone Miner Res 2002; 17: 1680-1690

26 Parker D, Planet PJ, Soong G, et al. Induction of type I interferon signaling determines the relative pathogenicity of Staphylococcus aureus strains. PLoS Pathog 2014; 10: e1003951.

27 Bonderman D, Jakowitsch J, Redwan B, et al. Role for staphylococci in misguided thrombus resolution of chronic thromboembolic pulmonary hypertension. Arterioscler Thromb Vasc Biol 2008; 28: 678-684.

28 Alias S, Redwan B, Panzenböck A, et al. Defective angiogenesis delays thrombus resolution: a potential pathogenetic mechanism underlying chronic thromboembolic pulmonary hypertension. Arterioscler Thromb Vasc Biol 2014; 34: 810-819.

29 Frey MK, Alias S, Winter MP, et al. Splenectomy is modifying the vascular remodeling of thrombosis. J Am Heart Assoc 2014; 3: e000772.

30 Wynants M, Vengethasamy L, Ronisz A, et al. NF- $\kappa \mathrm{B}$ pathway is involved in CRP-induced effects on pulmonary arterial endothelial cells in chronic thromboembolic pulmonary hypertension. Am J Physiol Lung Cell Mol Physiol 2013; 305: L934-L942.

31 Wynants M, Quarck R, Ronisz A, et al. Effects of C-reactive protein on human pulmonary vascular cells in chronic thromboembolic pulmonary hypertension. Eur Respir J 2012; 40: 886-894.

32 Bernard J, Yi ES. Pulmonary thromboendarterectomy: a clinicopathologic study of 200 consecutive pulmonary thromboendarterectomy cases in one institution. Hum Pathol 2007; 38: 871-877.

33 Blauwet LA, Edwards WD, Tazelaar HD, et al. Surgical pathology of pulmonary thromboendarterectomy: a study of 54 cases from 1990 to 2001. Hum Pathol 2003; 34: 1290-1298.

34 Mercier O, Fadel E. Chronic thromboembolic pulmonary hypertension: animal models. Eur Respir J 2013; 41: 1200-1206.

35 Mercier O, Tivane A, Dorfmüller P, et al. Piglet model of chronic pulmonary hypertension. Pulm Circ 2013; 3: 908-915. 